\title{
DA COISA — DE SE A FREQUENTAM OUTRAS COISAS
}

“[...] mestre, meu coração não aprendeu a tua serenidade."

(Álvaro de Campos)

\author{
Jeovane Camargo ${ }^{1}$ \\ Universidade Federal de São Carlos (UFSCar) \\ (iD) https://orcid.org/0000-0002-6960-6110 \\ E-mail: acasadeasterion@gmail.com
}

\section{RESUMO:}

Propomos investigar a originalidade da poesia de Alberto Caeiro, heterônimo de Fernando Pessoa, frente ao pensamento moderno e contemporâneo. Ao aliar uma experiência original da realidade imediata, uma desaprendizagem das abstrações metafísicas/modernas e uma linguagem conciliada com as coisas elas mesmas, a poesia de Caeiro se mostra apta a figurar como uma superação possível das dicotomias características do pensamento moderno, como sujeito e objeto. Ela pode solucionar também os impasses da fenomenologia de Merleau-Ponty, como a articulação corpo e natureza e a passagem da experiência perceptiva muda à linguagem. Para tanto, consideramos pontualmente a experiência caeiriana da coisa, do corpo, da linguagem, e sua negação da Realidade como tempo e como desejo.

PALAVRAS-CHAVE: Coisa; Corpo; Tempo; Linguagem; Desejo.

\section{ON THE THING — ON IF OTHER THINGS HAUNT IT}

\begin{abstract}
:
This project investigates the originality of the poetry of Alberto Caeiro, one of Fernando Pessoa's heteronymous, within modern and contemporary thought. By combining an original experience of immediate reality, an unlearning of modern/metaphysic abstractions, and a language reconciled with things themselves, Caeiro's poetry can help transcend the dichotomies of modern thought, such those opposing subject and object. It can also solve some of the impasses of Merleau-Ponty's phenomenology, such as the articulation between body and nature, and the passage from a mute perceptual experience to language. Therefore, we consider the Caeirian experience of thing, body, language, and its denial of Reality understood as time and as desire.
\end{abstract}

KEYWORDS: Thing; Body; Time; Language; Desire.

${ }^{1}$ Doutor em Filosofia pela Universidade Federal de São Carlos (UFSCar), São Carlos - SP, Brasil.

CAMARGO, Jeovane. Da coisa - de se a frequentam outras coisas. Griot : Revista de Filosofia, Amargosa - BA, v.19, n.2, p.135-153, junho, 2019. 


\section{Introdução}

Estimulada por Renaud Barbaras, especialmente por seu artigo "Fenomenologia e literatura: a não filosofia de Fernando Pessoa"2, a pesquisa em Fernando Pessoa recebeu um importante impulso dentro dos departamentos de filosofia do Brasil e do exterior. A obra do poeta português não é apenas inspirada pela filosofia senão que expressa uma experiência poético-filosófica de enorme pertinência ${ }^{3}$. Barbaras foi também um dos primeiros ${ }^{4}$ a trazer à tona a originalidade da poesia de Alberto Caeiro, um dos heterônimos de Fernando Pessoa, e contrapô-la ao que havia ainda de impensado na fenomenologia, especialmente a de MerleauPonty. Segundo Barbaras, os problemas enfrentados por Merleau-Ponty, como a utilização de um vocabulário ainda dualista, o problema da passagem da percepção à linguagem e o da articulação entre corpo e Natureza, desaparecem na poesia de Caeiro, a qual se revela "uma tentativa única para dizer a coisa como pura presença" (BARBARAS, 2011, p. 223).

Os textos mais recentes ${ }^{5}$ de Barbaras apresentam ainda uma leitura inovadora da fenomenologia, ao conciliá-la com a noção de desejo. Por sua vez, Ramos e Saint Aubert encontram a noção de desejo já na obra de Merleau-Ponty, seja como uma dimensão do ser, seja como critério ontológico da carnalidade do mundo. Em nossa tese de doutorado, exploramos o desejo nas diferentes fases do pensamento merleaupontiano, integrando-o ora à estrutura temporal ora à sensibilidade da própria Natureza. Analisamos também as dificuldades encontradas por Merleau-Ponty para articular corpo e mundo e percepção e linguagem. Na primeira fase, um corpo que comportava a transcendência e uma Natureza sem produtividade; e uma linguagem que não era mais do que a tradução das emoções da existência anônima do corpo. Na última fase, uma Natureza cuja sensibilidade prescindia do corpo, o qual se tornava então tão somente um recorte do Ser total; e uma sensibilidade que já indicava nela mesma a reflexividade própria da linguagem, de modo que esta não seria mais do que a sublimação do mundo sensível.

Em sua obra, constituída por $O$ guardador de rebanhos, $O$ pastor amoroso e Poemas inconjuntos, Caeiro apresenta uma experiência do mundo, das coisas e de si mesmo cuja originalidade e importância consistem, primeiro, em uma experiência poética que é ela mesma a manifestação das coisas, o exterior ou o fora; segundo, em uma desaprendizagem das abstrações através das quais o homem moderno experimenta seu mundo, portanto, um reaprender a sentir; e, terceiro, no uso de uma linguagem desligada de todas as dicotomias características do pensamento ocidental,

\footnotetext{
${ }^{2}$ BARBARAS. Investigações Fenomenológicas - Em direção a uma fenomenologia da vida. Curitiba: UFPR, 2011.

${ }^{3}$ Fernando Pessoa se considerava mesmo "um poeta inspirado pela filosofia" (PESSOA, 2006a, p. 19). Contudo, não se trata com isso de dizer que a consciência filosófica preceda a experiência poética e a conduza, mas que o universo poético de Pessoa é original por integrar indissociavelmente filosofia e poesia. Por isso, Pessoa também entendia que ele era: "não um filósofo com faculdades poéticas" (PESSOA, 2006a, p. 19).

4 Outros autores também haviam traçado um paralelo entre fenomenologia, Merleau-Ponty e Caeiro. Por exemplo: Gilberto de Mello Kujawski, em Fernando Pessoa, o outro, de 1967, pg. 53; Jacinto Prado Coelho, em Diversidade e unidade em Fernando Pessoa, de 1977, p. 26; Georg Rudolf Lind, em Estudos sobre Fernando Pessoa, de 1981, pg. 119; Leyla Perrone-Moisés, no livro Aquém do eu, além do outro, de 1982, pg. 117; e Luís de Oliveira e Silva, no livro O materialismo idealista de Fernando Pessoa, de 1985, pg. 22.

${ }^{5}$ Por exemplo: BARBARAS. Le désir et la distance. Paris: Vrin, 1999; Introdution à une phnomeénologie de la vie. Paris : Vrin, 2008; La vie lacunaire. Pais: Vrin, 2011 ; e: Dynamique de la manifestation. Paris: Vrin, 2013.
}

CAMARGO, Jeovane. Da coisa - de se a frequentam outras coisas. Griot : Revista de Filosofia, Amargosa - BA, v.19, n.2, p.135-153, junho, 2019. 
tais como sujeito $e$ objeto, corpo $e$ espírito, razão $e$ experiência, intelecto $e$ sentidos, percepção e linguagem, corpo $e$ mundo, etc. Além disso, temos ainda o uso da tautologia, da ataraxia e do oximoro para explicitar o modo de ser das coisas, seu existir aquém das abstrações que nelas são projetadas. Dessa forma, Caeiro traz à tona uma compreensão original do corpo, do mundo e da linguagem, que parece ultrapassar não só o pensamento moderno, mas também os impasses da fenomenologia.

No conjunto da obra de Fernando Pessoa, Caeiro possui um lugar de destaque porque ele é assumido, pelos outros heterônimos e até mesmo por Pessoa ortônimo, como o mestre dos outros poetas que configuram o universo pessoano. Nas palavras de Álvaro de Campos, um dos principais heterônimos de Pessoa, temos:

Em torno do meu mestre Caeiro havia, como se terá depreendido destas páginas, principalmente três pessoas - o Ricardo Reis, o António Mora e eu. Não faço favor a ninguém, nem a mim, dizendo que éramos, e somos, três indivíduos, absolutamente distintos [...] E todos nós três devemos o melhor da alma que hoje temos ao nosso contacto com o meu mestre Caeiro. Todos nós somos outros - isto é, somos nós mesmos a valer - desde que fomos passados pelo passador daquela intervenção carnal dos Deuses. (PESSOA, 1990b, p. 369)

Isso se deve ao modo como Caeiro supera, em sua poesia, os prejuízos do pensamento moderno, dos quais os outros poetas ainda são reprodutores em algum grau. Ao comentar esse fato, Álvaro de Campos diz o seguinte:

O meu mestre Caeiro não era um pagão: era o paganismo. O Ricardo Reis é
um pagão, o António Mora é um pagão, eu sou um pagão; o próprio
Fernando Pessoa seria um pagão, se não fosse um novelo embrulhado para
o lado de dentro. Mas o Ricardo Reis é um pagão por carácter, o António
Mora é um pagão por inteligência, eu sou um pagão por revolta, isto é, por
temperamento. Em Caeiro não havia explicação para o paganismo; havia
consubstanciação. (PESSOA, 1980, p. 267)

Isso quer dizer que nos outros poetas ainda há elementos de negação, de abstração ou de irrealidade ${ }^{6}$. Elementos que desaparecem da poesia de Caeiro. Por isso, ele é visto como a consubstanciação do paganismo, isto é, ele não acredita no paganismo por alguma razão, mas existe, sente, vê totalmente afinado ao modo de ser pagão.

No que consiste, pois, o paganismo? O melhor esclarecimento vem de Ricardo Reis, o poeta que procura reconstruir em sua obra o mundo antigo, embora seja ao mesmo tempo afligido pela angústia de que tudo é em vão. Segundo Reis, o que distingue o paganismo greco-romano de outros tipos de paganismo é o "carácter firmemente objectivo que nele transparece, efeito de uma mentalidade que, embora

\footnotetext{
${ }^{6}$ Segundo Octávio Paz : “Caeiro é o sol e em tôrno dêle giram Reis, Campos e o próprio Pessoa. Em todos êles há partículas de negação ou de irrealidade: Reis acredita na forma, Campos na sensação, Pessoa nos símbolos. Caeiro não acredita em nada: existe. [...] Caeiro é tudo o que Pessoa não é e, além disso, tudo o que nenhum poeta moderno pode ser: o homem reconciliado com a natureza. Antes do cristianismo, sim, mas também antes do trabalho e da história. Caeiro nega, pelo mero fato de existir, não somente a estética simbolista de Pessoa como tôdas as estéticas, todos os valores, tôdas as idéias. Não fica nada? Fica tudo, limpo todos os fantasmas e teias de aranha da cultura." (PAZ, 1976, p. 209)
}

CAMARGO, Jeovane. Da coisa - de se a frequentam outras coisas. Griot : Revista de Filosofia, Amargosa - BA, v.19, n.2, p.135-153, junho, 2019. 
diferente nos dois povos, tinha de comum a tendência para colocar na Natureza exterior $[\ldots]$ o critério da Realidade". Por isso, para reconstruir o paganismo, a primeira ação é "fazer renascer o objectivismo puro dos gregos e romanos" (PESSOA, 1996, p. 231). Tal caráter objetivo do paganismo é diverso da objetividade cientifica moderna, na qual "objetivo" significa a observação e o registro de eventos inseridos em um pensamento operatório com fins práticos. $O$ objetivismo grego-romano significa ver a Natureza sem abstrações, sem teorias ou conceitos construídos que a obnubilam ao invés de a revelarem. Mesmo o panteão de divindades do mundo antigo não deve ser visto como mística ou desvio da Natureza exterior, pois, para um pagão, os deuses sempre aparecem, seja como raio, vento ou um riacho, seja como inveja, raiva ou inteligência. Tudo o que lhes aparece é exterior; também os desuses, enquanto a Realidade vista e vivida, são exterior. Por isso, diz Álvaro de Campos que Caeiro foi a "intervenção carnal dos deuses" em relação aos outros poetas do universo pessoano. A sensibilidade própria de Caeiro não lhes foi algo somente abstrato, lido, pensado, mas uma realidade exterior, algo que eles sentiram, experimentaram. Nesse sentido, comenta Reis que compreender o paganismo com a inteligência não torna alguém pagão ou neopagão: “Tem o indivíduo que nascer com a inteligência para compreendê-las [as coisas do paganismo] colocada no centro de sua sensibilidade" (PESSOA, 1996, p. 231). Caeiro era o possuidor dessa "organização nativamente objectivista da inteligência e da sensibilidade", de maneira que, embora não se considerasse pagão, o era por força do que experimentava, do que via e sentia. É isso que Álvaro de Campos entende ao dizer que de Caeiro emanava um "estranho ar grego", um ar limpo, claro e calmo que vinha "de dentro", isto é, que era o sentir mesmo de Caeiro. No poema "Mestre, meu mestre querido", Álvaro de Campos, o poeta da insatisfação moderna, se refere ao ar grego de Caeiro utilizando o termo "serenidade":

\footnotetext{
"Meu mestre e meu guia!/ A quem nenhuma coisa feriu, nem doeu, nem perturbou,/ Seguro como um sol fazendo o seu dia involuntariamente,/ Natural como um dia mostrando tudo,/ Meu mestre, meu coração não aprendeu a tua serenidade." (PESSOA, 2012, p. 323; grifo meu)
}

É esse objetivismo, essa imediata experiência das coisas, essa sensibilidade postada na Realidade, na Natureza exterior, a raiz da originalidade de Caeiro. A realidade imediata que constitui o elemento de sua sensibilidade é não mística, não abstrata, não construída, não metafísica e não filosófica (num mau sentido), e por isso mesmo ela é o exterior, o fora, as coisas elas mesmas. A poesia de Caeiro ensina a desaprender tudo o que seja abstrato, moderno, ou seja, tudo que é não coisa.

Em face disso, procuramos investigar como a experiência poética de Caeiro pode se apresentar como um possível ultrapassamento dos impasses da fenomenologia assim como das dicotomias do pensamento moderno. Nossa questão norteadora é a seguinte: como a realidade imediata apresentada por Caeiro, ao mostrar que a coisa é só o que ela é, pode se revelar a superação de noções como intencionalidade, temporalidade, corpo próprio, quiasma ou carne, apresentadas pela fenomenologia como a estrutura ontológica própria da experiência?7 Como já ${ }^{7}$ E até mesmo de desejo, tal como este aparece em Barbaras. Ver, por exemplo: Le désir et la distance (1999), La
vie lacunaire (2011) e Investigações Fenomenológicas (2011).

CAMARGO, Jeovane. Da coisa - de se a frequentam outras coisas. Griot : Revista de Filosofia, Amargosa - BA, v.19, n.2, p.135-153, junho, 2019. 
percorremos toda a obra merleau-pontiana em nosso doutorado, explorando os mesmos conceitos que serão indicados a seguir, o percurso deste artigo se concentrará principalmente na poesia de Caeiro, embora sempre se pontue suas diferenças e similitudes com o pensamento de Merleau-Ponty. Nosso percurso será pois o seguinte em relação à poesia de Caeiro: I - Considerar como se configura sua noção de coisa; II - Investigar sua negação da noção de tempo; III - Determinar, em sua poesia, o que é corpo; IV - Delimitar o caráter imediato e não instrumental de sua linguagem; e V - Explicitar sua negação da realidade entendida como desejo.

I - Em Merleau-Ponty, a experiência perceptiva se realiza como relação entre corpo e mundo. $\mathrm{O}$ corpo recorta um ponto de vista em meio às coisas e estas exigem dele uma determinada tomada ${ }^{8}$. $\mathrm{O}$ mundo possui um sentido autóctone, o qual se dá no comércio entre os poderes do corpo (suas equivalências sensoriais) e as $\operatorname{coisas}^{9}$. É essa relação que a Fenomenologia da percepção $(\mathrm{PhP}, 1945)$ denomina ambiguidade entre corpo e mundo, e que também determina a noção de mundo natural: “o mundo natural [...] é a típica das relações intersensoriais" (MERLEAU-PONTY, PhP, p. 438). Quando vejo um livro, sei também que ele possui faces que não são vistas por mim atualmente, mas que podem ser vistas se eu der a volta. Uma coisa vista anuncia outras possibilidades perceptivas para além de sua tomada atual. $\mathrm{O}$ livro em cima da mesa é frequentado por outras perspectivas que o corpo pode assumir se mudar de posição; o livro visto reenvia a "tudo aquilo que os outros [objetos] 'vêem" dele" (MERLEAU-PONTY, PhP, p. 105), ele reenvia a outros pontos de vista possíveis. Isso quer dizer que ver é um poder de habitar o objeto "e dali apreender todas as coisas segundo a face que elas voltam para ele" (MERLEAU-PONTY, PhP, p. 105). Nesse sentido, perceber, ver uma coisa, é "apreender um sentido imanente aos signos antes de qualquer juízo" (MERLEAU-PONTY, PhP, p. 63; grifo meu). Por "sentido imanente aos signos" deve-se entender que a coisa é frequentada por possibilidades perceptivas que ainda não se atualizaram, mas que se anunciam na coisa vista, de maneira que ela está "grávida" de outras possibilidades. A "síntese de horizontes" que realizo deixa o objeto aberto, sendo sempre possível outro ponto de vista sobre ele. Além disso, desde que a coisa se oferece segundo as equivalências sensoriais do corpo, ela é então uma visão minha, um recorte operado pelo esquema corporal em face do mundo - concepção que aparece nas diferentes fases do pensamento merleau-pontiano ${ }^{10}$.

Ora, mas como é que sabemos que há dimensões que se anunciam (frequentam) uma coisa vista? De onde tiramos esse saber de algo que não experimentamos em momento algum, a não ser como abstração do pensamento? Como é que sabemos que

\footnotetext{
8 "O sensível me restitui aquilo que lhe emprestei, mas é dele mesmo que eu o obtivera" (Merleau-Ponty, PhP, p. $289)$.

9 "Existe um sentido autóctone do mundo, que se constitui no comércio de nossa existência encarnada com ele, e que forma o solo de toda Sinngebung decisória" (MERLEAU-PONTY, PhP, p. 591).

${ }^{10}$ Segundo a PhP: "A coisa e o mundo só existem vividos por mim ou por sujeitos tais como eu, já que eles são o encadeamento de nossas perspectivas [...]" (MERLEAU-PONTY, PhP, p. 447; grifo meu). E segundo o VI: "Pois se é certo que vejo minha mesa, que minha visão termina nela, que ela fixa e detém meu olhar com sua densidade insuperável, [...] é certo também que esta certeza é combatida, desde que atento para ela, porquanto se trata de uma visão minha" (MERLEAU-PONTY, VI, p. 17).
}

CAMARGO, Jeovane. Da coisa - de se a frequentam outras coisas. Griot : Revista de Filosofia, Amargosa - BA, v.19, n.2, p.135-153, junho, 2019. 
passado e futuro frequentam a coisa? Como é possível ver na coisa algo que ali não está? Essas são questões que, embora não originariamente endereçadas à fenomenologia, resultam do modo como Caeiro experimenta as coisas.

Na poesia de Caeiro, temos uma experiência das coisas radicalmente diversa da de Merleau-Ponty. Sentir não é apreender um "sentido autóctone do mundo" (MERLEAU-PONTY, PhP, p. 591), no sentido de se apreender um campo de horizontes estruturado segundo perfis temporais recortados pelo ponto de vista assumido pelo corpo. Sentir é ver, tocar, ouvir uma coisa tal como ela é, tal qual ela se apresenta. Nesse sentido, diz Caeiro: “A espantosa realidade das coisas/ É a minha descoberta de todos os dias./ Cada coisa é o que é,/ E é difícil explicar a alguém quanto isso me alegra,/ E quanto isso me basta" (PESSOA, 2005, p. 91). As coisas são espantosas não por reenviarem (anunciarem) umas às outras, mas justamente por serem o que são, ou o que cada uma é. Não se deseja explicar seu funcionamento por meio de teorias científicas ou sistemas filosóficos, pois elas não têm nada por trás de si que seja seu fundamento ou sua estrutura ontológica. Não se deseja ver mais que as coisas, mais do que aquilo que aparece. Por isso, ver a coisa como ela é, basta, pois essa é a experiência da realidade - a experiência que deixa as coisas elas mesmas aparecerem, sem pôr nelas nada de abstrato, de pensamento ou de teoria ${ }^{11}$.

Nesse sentido, se num momento derradeiro alguém (Deus, por exemplo) perguntar o que é que se viu nas coisas, a resposta é: tão somente as coisas. "E se Deus me perguntar: o que viste tu nas coisas?/ Respondo: apenas as coisas... Tu não puseste lá mais nada./ E Deus, que é da mesma opinião, fará de mim uma nova espécie de santo" (PESSOA, 2005, p. 90). O aparecimento da figura divina nos versos não é sintoma de algum misticismo do poeta. Deus é apenas outra maneira de dizer Universo, isto é, a Realidade, a Natureza, a experiência das coisas, o sentir cada coisa. Essa Realidade, tal como Deus, não é feita por um sujeito, não é imanente nem depende dele, senão que ela é transcendente, isto é, aquilo que o sujeito não domina. É ela que se apropria do sentir de cada homem, obrigando-os ao seu modo de ser, ao seu aparecer, qual seja, que cada coisa é tão somente o que é. Assim, "só a Natureza é divina, e ela não é divina" (PESSOA, 2005, p. 52). Ela é divina porque ela é que manda, que se apropria do sentir de cada homem, restando a eles obedecer. Uma coisa aparece sem que o homem a deseje ou a faça aparecer. Ela se impõe a ele, subjuga-o. Mas ela não é divina no sentido das coisas místicas, como um ser suprassensível por trás das coisas e que as sustentaria.

Ora, se tal Realidade obriga o sentir humano, se o homem não a faz, então ela existe sem ele — independentes desse outro polo que seria o sujeito-humano. "Quando vier a primavera,/ Se eu estiver morto,/ As flores florirão da mesma maneira/ $\mathrm{E}$ as árvores não serão menos verdes que na primavera passada./ A realidade não precisa de mim" (PESSOA, 2005, p. 96). À primeira vista, estes versos parecem afirmar que a Natureza ou as coisas continuariam a existir mesmo que os homens desaparecessem. Mas o que se diz é que o eu (mim) não é o outro polo de uma relação que se daria entre as coisas $e$ o sujeito (mesmo quando este é entendido como corpo). Não precisar do sujeito (dentro, eu) significa, portanto, que uma coisa

\footnotetext{
11 Segundo Barbaras (2011, p. 223): "Há em Pessoa [Caeiro], uma tentativa única para dizer a coisa como pura presença/ excluindo a significação [...] ele não diz apenas que as coisas não significam nada, mas também que o próprio ser da coisa consiste em excluir a significação".
}

CAMARGO, Jeovane. Da coisa - de se a frequentam outras coisas. Griot : Revista de Filosofia, Amargosa - BA, v.19, n.2, p.135-153, junho, 2019. 
aparece tal qual ela é, ou seja, sem ser a perspectiva (ponto de vista) de um corpo ou a projeção das formas puras da sensibilidade de um sujeito transcendental. "A realidade não precisa de mim": ela se faz, não pede meu assentimento; não se oferece como meu ponto de vista, como uma visão minha. Ao contrário, no seu aparecer, cada coisa toma integralmente a visão, a audição, o tato, de maneira que sentir não é nada para dentro (ou interno), senão que somente o fora, o aparecimento de alguma coisa.

Nesse sentido, intensificando seu sentir, diz Caeiro: “A única afirmação é ser./ E só o afirmativo é que não precisa de mim" (PESSOA, 2005, p. 114; grifo meu). Por que só o afirmativo é que não precisa de mim? O que é o afirmativo? Ora, o afirmativo é ser. Não uma substância, matéria, átomo, alma ou sujeito transcendental. Mas ser no sentido de existir, de existir sem mais, sem abstrações que se pretendem solucionadoras do tal mistério do existir ${ }^{12}$. Assim, a única afirmação é o existir que a cada vez existe, ou seja, cada coisa no seu aparecer, inclusive o corpo e as ideias. Esse existir (ser, afirmação, afirmativo) é que não precisa de mim (homem, sujeito, corpo-ponto-de-vista) para existir. Ele existe gratuitamente, sem porquê, sem fundamento por trás que explique seu existir, sua afirmação. Não há um sujeito que, como o outro polo de uma relação, constitua o real, nem mesmo um corpo com o qual o mundo entraria em relação, de maneira que nesta se configuraria a experiência humana. Um tal existir (ser) é o afirmativo porque ele vem a ser por si mesmo, gratuitamente, ou seja, ele é a cada vez sem outro algo por trás que o faça ser — nas palavras do poeta: o existir, ser, "não precisa de mim". Se o existir não precisa entrar em contato com outro polo para se manifestar, e se ele é o que a cada vez se afirma por si mesmo (existe), então só resta àquele que sente aquiescer a esse fato.

Em vista disso, expõe Caeiro: "Nasço, vivo, morro por um destino em que não mando,/ Sinto, penso, movo-me por uma força exterior a mim" (PESSOA, 2005, p. 155; grifo meu). Não tenho controle sobre o que existe, tanto em relação à minha vida individual como em relação às coisas/eventos que me cercam. Não mando em meu destino, que é o de sentir, ser consciente de que existo e de que as coisas existem $^{13}$. Esse destino me é exterior, ele se faz, se impõe, me obriga, restando que eu a ele aceda. As coisas aparecem sem pedir licença, subjugam meu sentir, aparecem e se impõem como tais. Como não tenho poder sobre seu aparecer, resta-me aquiescer às sua afirmação/aparição. Esse é o destino de ser homem — a coisa aparece, obriga ao seu aparecer, apropria-se do sentir humano. Por isso, diz Caeiro que o Universo é "tão sublimemente não-meu" (PESSOA, 2005, p. 120).

II - A partir da realidade exposta por Caeiro, não se pode entender que haja passagem de uma coisa à outra, como se a manifestação de uma coisa fosse o

\footnotetext{
12 “O mistério das cousas? Sei lá o que é mistério!/ O único mistério é haver quem pense no mistério." (PESSOA, 2005, p. 23)

13 "Sim, tenho consciência da planta e ela não a tem de mim./ Mas se a forma da consciência é ter consciência, que há nisso?/ A planta, se falasse, podia dizer-me: e o teu perfume?/ Podia dizer-me: tu tens consciência porque ter consciência é uma qualidade humana/ E eu não tenho consciência porque sou flor, não sou um homem" (PESSOA, 2005, p. 130). Ser consciência é o mais natural do homem, assim como da flor é florir. Por isso, o homem existe "Tendo pensamentos por os ter [naturalmente]/ Como uma flor tem perfume e cor..." (PESSOA, 2005, p. 21).
}

CAMARGO, Jeovane. Da coisa - de se a frequentam outras coisas. Griot : Revista de Filosofia, Amargosa - BA, v.19, n.2, p.135-153, junho, 2019. 
desdobramento de perfis temporais. Quando uma coisa aparece, isso não significa que ela passou paulatinamente de um estado escondido (fundo) a um estado visto (figura). Ela aparece apenas. A passagem paulatina do fundo à figura é algo que não se experimenta, não se vê, não se sente - embora haja com cada coisa que aparece um fundo de outras coisas. Segundo Caeiro, não se vê uma coisa separada das outras, mas cada coisa é vista entre outras coisas. Nesse sentido, haveria uma temporalidade, intencionalidade, perpassando as coisas?

Em Merleau-Ponty, sentido é "quando um ou vários termos existem como... representantes de outra coisa que eles mesmos" ( $\mathrm{PhP}$, p. 574; grifo meu). Isso quer dizer que na coisa vista se anunciam outras coisas, que a frequentam outras possibilidades perceptivas, que ela é mais do que ela mesma, posto que está "grávida" de outras possibilidades, as quais podem se tornar atuais se o corpo mudar de ponto de vista. Assim, uma coisa aparece como outra, isto é, ela representa ou expressa não apenas a si mesma, senão que também as outras coisas (virtualidades perceptivas) que a frequentam. Essa noção de sentido ${ }^{14}$ é consequência da noção de temporalidade, a qual é um "ir além" que supera retomando. No seu desdobramento prospectivo se anunciam possibilidades futuras, e no seu desdobramento retrospectivo ainda se conservam possibilidades perceptivas que vieram ao presente e passaram, mas que podem ser retomadas. Dessa forma, o presente é mais do que ele mesmo, pois ele é frequentado pelo passado e pelo futuro. Segundo a PhP, "o presente vivo está dilacerado entre um passado que ele retoma e um porvir que [ele] projeta" (MERLEAU-PONTY, PhP, p. 447). O movimento temporal de ir além torna o presente aquilo que ele será e ao mesmo tempo o conserva como aquilo que ele foi, ou seja, faz passado e futuro se anunciarem no momento presente. Nesse sentido, tanto a coisa como sua dimensão ontológica (o presente) são mais do que eles mesmos; e, portanto, não são o que são, porque são a insatisfação de não ser ainda algo que neles se anuncia, ou seja, são a insatisfação de não ser outra coisa que eles mesmos ${ }^{15}$. A maneira como a noção de desejo (insatisfação) aparece articulada intimamente com a noção de temporalidade foi largamente explorada em nossa tese de doutorado, a qual realiza essa análise percorrendo as diferentes fases do pensamento de Merleau-Ponty.

Por sua vez, de modo singelo e objetivo, como são as coisas que aparecem, Caeiro faz o seguinte comentário a respeito de um tempo (temporalidade) inscrito nas próprias coisas: "Quero as cousas que existem, não o tempo que as mede./ O que é o presente?/ É uma cousa relativa ao passado e ao futuro./ É uma cousa que existe em virtude de outras cousas existirem./ Eu quero só a realidade, as cousas sem presente" (PESSOA, 2005, p. 152). As coisas enquanto atravessadas pela temporalidade, como presentes, são abstrações. O tempo concebido como passagem, movimento que perpassa as coisas, é um modo tardio de ver. É acrescentar às coisas o que elas não são; é "pôr nomes errados às cousas" (PESSOA, 2005, p. 109). É dizer a "manhã raia" quando de fato é o sol que raia; é dizer temporalidade, intencionalidade, frequentação de possibilidades perceptivas quando de fato esses conceitos não são realidades imediatas, não são visíveis ou experimentados.

\footnotetext{
14 "Sob todas as acepções da palavra sentido, nós reconhecemos a mesma noção fundamental de um ser orientado ou polarizado em direção àquilo que ele não é [...]" (MERLEAU-PONTY, PhP, p. 576; grifo meu).

${ }^{15}$ Em Barbaras, esse modo metafísico de pensar a Realidade se condensa e alarga em seu conceito de désir, como será exposto ao final deste artigo.
}

CAMARGO, Jeovane. Da coisa - de se a frequentam outras coisas. Griot : Revista de Filosofia, Amargosa - BA, v.19, n.2, p.135-153, junho, 2019. 
Tais perfis temporais da coisa são momentos abstratos, acrescentados ao seu aparecer. Nesse sentido, alerta Caeiro: "O que nós vemos das cousas são as cousas./ Por que veríamos nós uma cousa se houvesse outra?" (PESSOA, 2005, p. 49). Se houvesse outra coisa para ver, ela seria vista, e não a coisa que de momento se vê. Ver outras coisas em uma coisa é algo do pensamento, da memória, isto é, está do lado de quem vê, não na coisa vista. Assim: " $\mathrm{O}$ Tejo tem grandes navios/ E navega nele ainda,/ Para aqueles que veem o que lá não está,/ A memória das naus" (PESSOA, 2005, p. 45). As coisas não tem memória; se se rememora algo a partir de uma coisa vista, o rememorar é já tardio em relação ao aparecer da coisa. Nesse sentido é que o poeta diz que memória é ver o que lá não está. Assim, "o que foi não é nada, e lembrar é não ser" (PESSOA, 2005, p. 69). O que "foi”, a lembrança, o passado, está do lado de quem vê; não é a coisa na sua imposição de coisa.

A coisa é realidade imediata, o que se impões ao olhar, ouvir, sentir. Se se pode dizer que ela transcende, não é porque ela seja passagem temporal ou intencional, senão porque ela não depende de um sujeito (corpo), sendo pois aquilo que o transcende, que o obriga ao seu modo de ser. Por isso: "Eu nunca passo para além da realidade imediata./ Para além da realidade imediata não há nada" (PESSOA, 2005, p. 101).

Passar para além da realidade imediata significa ser místico, isto é, ver o que lá não está, acrescentar coisas à coisa, errar: "Tu, místico, vês uma significação em todas as cousas./ Para ti tudo tem um sentido velado./ Há uma cousa oculta em cada cousa que vês./ O que vês, vê-lo sempre para veres outra cousa" (PESSOA, 2005, p. 135). As "significações" que se veem em uma coisa são as possibilidades ou coisas que a frequentam, às quais ela reenvia, as quais se oferecem como "promessa" de outra coisa que ela mesma. Todavia, nada disso é realidade imediata, nada disso é visto; por isso o poeta chama esse modo de sentir de mística, certa abstração que consiste em ver nas coisas o que nelas não aparece.

Por que se cai nessas abstrações? Como ver pode ser também mística? Porque deixamos de ver a coisa para vermos o que nela projetamos, isto é, a esquecemos para vermos a nós mesmos. Nos versos de Caeiro, temos então:

\footnotetext{
Navio que partes para longe,/ Por que é que, ao contrário dos outros,/ Não fico, depois de desapareceres, com saudades de ti?/ Porque quando te não vejo, deixaste de existir./ E se se tem saudades do que não existe,/ Sente-se em relação a cousa nenhuma;/ Não é do navio, é de nós, que sentimos saudades. (PESSOA, 2005, p. 124; grifo meu)
}

Se, ao olhar o porto, se tem saudades do navio que ali havia atracado, isso não quer dizer que o próprio porto desperte ou seja frequentado por uma memória. As saudades do navio que ali estava são de fato apenas saudades de uma vivência do observador, de algo que ele viveu. Ter saudades de outra coisa no momento em que se está vendo uma coisa é ter saudades de um momento passado em que se via aquela outra coisa. $O$ momento passado não está na coisa; está, pois, só na lembrança de quem o viveu. Assim, o passado, ou a coisa passada, não pode estar na coisa vista; e do mesmo modo o futuro também não se anuncia nela, o que seria ver na coisa o que ela não é, mas o que o observador espera, pensa ou imagina. Por fim: "A recordação é uma traição à Natureza,/ Porque a Natureza de ontem não é Natureza./ O que foi

CAMARGO, Jeovane. Da coisa - de se a frequentam outras coisas. Griot : Revista de Filosofia, Amargosa - BA, v.19, n.2, p.135-153, junho, 2019. 
não é nada, e lembrar é não ver" (PESSOA, 2005, p. 69). Ver na coisa um pretenso passado dela mesma é não vê-la, pois assim se projeta nela o que é pensamento (ou as lembranças que se tem de si mesmo). Ao se ver a coisa por meio de uma recordação, trai-se a coisa ou a Natureza, pois a memória é algo acrescentado, secundário e tardio em relação ao aparecer da coisa. Assim, lembrar é não ver, pois o passado ou a lembrança estão do lado de quem vê, não na coisa.

III - O corpo, em Merleau-Ponty, é o "fundo" em face do qual as coisas aparecem. Embora as coisas sejam elas mesmas, elas são todavia uma visão minha, o recorte operado por meus "Eus naturais", meus sentidos e suas equivalências. A ambiguidade entre corpo e mundo significa que, embora o mundo também exija uma determinada tomada, o corpo é o "lugar" onde se realiza a "integralização" de uma série de possibilidades perceptivas, uma "síntese de horizontes" que configura a visão atual de um campo de experiências. Manifestar-se segundo o ponto de vista do corpo, ou como uma visão minha, quer dizer se oferecer segundo o "sistema de equivalências" que é o corpo humano. Já na segunda fase de Merleau-Ponty, apresenta-se uma Natureza, "Ser bruto", carne ou quiasma que possui uma sensibilidade tal que prescinde mesmo do testemunho humano, e do qual o corpo emerge como um recorte, ou um modo possível em relação ao "Ser total". Mesmo a reflexibilidade própria do corpo humano e da linguagem já está indicada no sensível, como, por exemplo, no mimetismo animal ${ }^{16}$.

Ora, mas desde que, em Caeiro, a coisa é só o que ela é, não sendo frequentada por outras coisas, e que a realidade não comporta nenhuma temporalidade, o que vem a ser então corpo? Se a perspectiva e o ponto de vista são atrasados em relação à coisa, o que vem a ser corpo, para que ele não seja o fundo em face do qual as coisas aparecem?

Em Caeiro, o corpo comporta um alargamento de sentido que lhe possibilita não ser o outro lado, o ponto de vista ou o fundo em relação ao qual as coisas aparecem. Não sendo o outro polo do mundo, nem um recorte da sensibilidade da Natureza, o corpo é o fora, o exterior. Isso implica que a realidade não é pensada como a relação entre corpo e mundo, ou seja, que a noção de relação (corpo $e$ mundo) é tardia face ao que se manifesta, à coisa ela mesma. Esta é somente exterior, sem comportar qualquer tipo de interioridade.

$\mathrm{O}$ que existe, existe exteriormente, mesmo a vida psíquica ou os sentimentos que habitualmente se considera estarem do lado de dentro, serem íntimos de um sujeito. Intenções, sentimentos, opiniões, o escuro dos olhos fechados, as figuras imaginárias não estão dentro, atrás do olhar; eles são pois modos de aparecer do fora. Eles não são certa "membrana inaparente", avesso, ou dimensão ausente de determinada manifestação do ser, tal como Merleau-Ponty assume em sua segunda fase. Eles são o fora em seu aparecer mesmo. Nesse sentido, congelando toda a interioridade por trás da noção de vida psíquica, diz Caeiro:

\footnotetext{
${ }^{16}$ Os animais reproduzem em seu próprio corpo os aspectos mais característicos do seu ambiente, das relações que mantém entre si e com seu meio. Por exemplo, a plumagem de um pássaro o camufla no tronco das árvores de uma dada vegetação, reproduzindo em seu corpo as cores de seu ambiente. O que quer dizer que ele não apenas vê, senão que também é visível, embora não tenha saber tético disso. Tal caráter de ver e ser visto seria um tipo de reflexividade da própria Natureza. Por sua vez, o sentir humano seria o nível tético dessa reflexividade.
}

CAMARGO, Jeovane. Da coisa - de se a frequentam outras coisas. Griot : Revista de Filosofia, Amargosa - BA, v.19, n.2, p.135-153, junho, 2019. 
Pastor do monte, tão longe de mim com as tuas ovelhas — / Que felicidade é essa que pareces ter - a tua ao a minha?/ A paz que sinto quando te vejo, pertence-me ou pertence-te?/ Não, nem a ti nem a mim, pastor./ Pertence só à felicidade e à paz./ Nem tu a tens, porque não sabes que a tens./ Nem eu a tenho, porque sei que a tenho./ Ela é ela só, e cai sobre nós como o sol [...] (PESSOA, 2005, p. 136)

A felicidade e a paz, exemplos de vida psíquica, não estão dentro do pastor do monte ou do poeta, mas sempre já fora, como o sol é fora. Assim como o sol cai sobre as personagens do poema, a felicidade e a paz não vêm do interior do poeta ou do pastor, mas são um sentir tal como sentir as coisas, as quais aparecem exteriormente. Um sentimento não se dá dentro, mas aparece, se faz, se apresenta. Ele é sempre um modo de ser segundo o qual o corpo se realiza. Assim, se o sentimento é modo de ser corpo, ele é enfim corpo, o exterior em seu aparecer. Em outro poema, temos:

\footnotetext{
"Seja o que for que esteja no centro do mundo,/ Deu-me o mundo exterior por exemplo de Realidade,/ E quando digo "isto é real", mesmo de um sentimento,/ Vejo-o sem querer em um espaço qualquer exterior,/ Vejo-o com uma visão qualquer fora e alheio a mim." (PESSOA, 2005, p. 136; grifo meu)
}

Mesmo o que chamamos sentimentos, os quais entendemos como interiores, não se passam dentro, senão que aparecem como as coisas aparecem, sempre fora. Isso não significa que tais sentimentos sejam exteriorizados, mas antes que eles aparecem sempre já fora, que eles são exteriores tal como a Realidade (as coisas) é sempre exterior.

Nesse sentido, "ser real quer dizer não estar dentro de mim" (PESSOA, 2005, p. 119). Da pessoa de dentro não há como ter noção de realidade, ela nunca se mostra como realidade imediata, nunca se oferece aos sentidos. Por outro lado, o corpo é uma realidade imediata: ele pode ser visto, tocado, estar de pé ou sentado. Contudo, isso não representa uma descrição fenomenológica do corpo, a qual tentaria mostrar seu imbricamento ou ambiguidade em relação ao mundo e seu entrecruzamento de tecidos ou equivalências sensoriais, estrutura ontológica que em Merleau-Ponty é denominada carne, quiasma e ser no mundo. E se a coisa existe "independentemente de mim/ Sem precisar de mim para existir" (PESSOA, 2005, p. 119), isso também não significa uma Natureza que existiria mesmo sem o testemunho humano. Antes, isso quer dizer que, originariamente, as coisas não se oferecem em relação à perspectiva ou ponto de vista corporal. O ponto de vista é um modo de entender já tardio, uma abstração face ao aparecer imediato da coisa. A coisa, pois, obriga o corpo ao seu aparecimento; em relação ao seu aparecer, o corpo sempre já aquiesceu; esse é o destino, a imposição que todo aparecer realiza. Isso é ser corpo, ter já acedido à coisa; ser já o exterior que ela é; ser o fora de todo aparecimento. Corpo é, portanto, ser "exterior essencialmente" (PESSOA, 2005, p. 120).

O corpo enquanto conjunto de órgãos ou o olhar enquanto órgão que capta um estímulo exterior são construções secundárias face ao exterior. Na linguagem do poeta, um tal corpo e tais órgãos dos sentidos (órgãos fisiológicos) são estar doente do sentir - assim como o mundo moderno, ao esquecer-se da realidade imediata, está

CAMARGO, Jeovane. Da coisa - de se a frequentam outras coisas. Griot : Revista de Filosofia, Amargosa - BA, v.19, n.2, p.135-153, junho, 2019. 
apenas às voltas com abstrações místicas (tempo/espaço, órgãos/condutos, real/substância, energia/átomo/verdade, etc.). Nesse sentido, diz Caeiro:

A noite desce, o calor soçobra um pouco./ Estou lúcido como se nunca
tivesse pensado/ E tivesse raiz, ligação direta com a terra,/ Não esta espúria
ligação do sentido secundário chamado a vista,/ A vista por onde me separo
das cousas,/ E me aproximo das estralas e das cousas distantes-/ Erro:
porque o distante não é o próximo,/ E aproximá-lo é enganar-se.
(PESSOA, 2005, p. 115)

A vista, enquanto órgão da fisiologia corporal, é já um momento segundo, atrasado em relação à Realidade exterior. Por isso, entendida cientificamente, antes ela separa das coisas, perde-as, do que as revela. Não há um órgão do sentir (vista) que captaria um estímulo exterior e o conduziria a um centro nervoso. Esse modo de pensar é já atrasado. É antes acrescentar algo às coisas que as ver.

Ao comentar certas conjecturas de Ricardo Reis, Caeiro diz que ele também sabe fazer conjecturas. Todavia, suas "conjecturas" acabam enfim expondo outra vez a realidade imediata, o exterior. Em relação ao corpo, temos a seguinte conjectura: "Também sei fazer conjecturas./ Há em cada coisa aquilo que ela é que a anima./[...]/ No homem é a alma que vive com ele e é já ele./ Nos deuses tem o mesmo tamanho/ E o mesmo espaço que o corpo/ E é a mesma coisa que o corpo" (PESSOA, 2005, p. 162). A conjectura diz respeito à questão do que anima as coisas. Como resposta a essa questão, temos possíveis conjecturas, mas que só são conjecturas na aparência, pois no limite elas falam da realidade imediata. Assim, o que anima o homem é a alma que "é já ele", ou seja, o que o anima é o fato de ele ser este homem que ele é: um corpo que pode ser visto e tocado, que está em pé ou sentado. Dessa forma, homem é o aquiescer a um modo de ser, o ser já um modo de ser (em pé, sentado, visto, dormir, escrever, pensar). E ser já disposto como um modo de ser (andar, falar, acordar) é corpo. "Que perfeito que é nele o que ele é - o seu corpo" (PESSOA, 2005, p. 141). Corpo é ser a cada vez obrigado por um modo de ser. Por sua vez, em relação aos deuses, o que os anima é aquilo que tem o mesmo tamanho e o mesmo espaço que o corpo, e que "é a mesma coisa que o corpo", isto é, o que os anima, o que eles são essencialmente, é o fato de serem eles corpo. Os deuses, no poema, não representam alguma mitologia ou mística do poeta, mas o caráter irrevogável do exterior, do aparecer das coisas; o destino de ser fora sempre e a cada vez. Ser corpo, em relação a um deus, significa aparecer como coisa, como exterior; "Por isso os deuses não têm corpo e alma/ Mas só corpo e são perfeitos" (PESSOA, 2005, p. 162). Em outro poema, temos:

E como a alma é aquilo que não aparece,/ A alma mais perfeita é aquela que não aparece nunca — A alma que está feita com o corpo/ $\mathrm{O}$ absoluto corpo das cousas,/ A existência absolutamente real sem sombras nem erros,/ A coincidência exacta e inteira de uma cousa consigo mesma. (PESSOA, 2005, p. 137)

Ser corpo é não ter atrás, interior, alma; é ser a existência absolutamente real, isto é, a realidade imediata; ser corpo, portanto, é a coincidência exata de uma coisa consigo mesma, ou seja, o aparecer de uma coisa, o exterior, o fora. Assim, não há dualismo entre ser e aparecer, entre dentro e fora, posto que corpo é o aparecer da

CAMARGO, Jeovane. Da coisa - de se a frequentam outras coisas. Griot : Revista de Filosofia, Amargosa - BA, v.19, n.2, p.135-153, junho, 2019. 
coisa. Isso acontece, "Porque eu sou do tamanho do que vejo/ E não do tamanho da minha altura..." (PESSOA, 2005, p. 27; grifo meu), ou seja, porque ser corpo é estar obrigado ao aparecer da coisa, àquilo que se vê. A especificidade do homem, sua diferença, em relação às plantas e aos animais é a de ele ser consciência. Não que haja uma passagem de um momento não consciente à consciência, senão que homem é ser sempre já testemunho da Realidade exterior. Ser consciência é o natural do homem, assim como da flor é ter perfume e cor. Por isso, o homem existe "Tendo pensamentos por os ter [naturalmente]/ Como uma flor tem perfume e cor..." (PESSOA, 2005, p. 21). Não há passagem do natural ao cultural, porque o cultural é o natural do homem; o que ele sempre já é.

IV - Na primeira fase do pensamento merleau-pontiano, encontramos o problema da passagem do movimento perceptivo anônimo à linguagem. Segundo alguns comentadores, na tentativa de solucionar esse problema, Merleau-Ponty reproduziu o dualismo moderno, fazendo descer no corpo uma consciência já possuidora das significações linguísticas - o que configuraria intelectualismo (Cf. MOURA, 2001, 313). Para outros, a linguagem se torna na PhP a tradução das emoções da existência anônima do corpo - o que representaria nomenclaturismo (Cf. Ferraz, 2009, p. 72). Esse problema foi percebido pelo próprio Merleau-Ponty, que, em $O$ visível e o invisível (VI, 1964), assim a ele se refere: "[...] (meu capítulo sobre o Cogito [na $\mathrm{PhP}$ ] não se liga ao capítulo sobre a palavra): ao contrário levantei um problema. [...] Fica o problema da passagem do sentido perceptivo ao sentido referente à linguagem, do comportamento à tematização (MERLEAUPONTY, VI, p. 171; grifo meu). Já na segunda fase de seu pensamento, Merleau-Ponty procura mostrar que a própria sensibilidade da Natureza antecipa a reflexibilidade própria da linguagem, de modo que na existência anônima encontra-se já uma "primeira linguagem" (MERLEAU-PONTY, PD, p. 43). Contudo, mesmo essa similitude estrutural entre percepção e linguagem ainda preserva um primeiro momento mudo, não linguístico, um "há prévio", em relação ao qual a linguagem seria a sublimação, um momento mais sutil. "Certamente é preciso haver dados perceptivos, uma experiência do mundo, para que o princípio discriminativo da fala atue de modo a elaborar um sistema de oposições linguísticas" (FERRAZ, 2009, p. 78; grifo meu). Por mais "fugidias" (não-simples, mas diacrítico-silenciosas) que sejam tais experiências sensíveis, há uma abertura tácita primeira que a linguagem delimita e diferencia segundo seus parâmetros culturais. De forma que o problema da passagem da percepção à linguagem não é portanto resolvido também nos últimos textos de Merleau-Ponty. Assim, segundo as anotações do Parcours Deux (19511961): “a abertura perceptiva não é linguística. É na percepção que ele [MerleauPonty] vê o lugar natal da fala" (MERLEAU-PONTY, PD, p. 274).

Por sua vez, em Caeiro, sensível e linguagem não são níveis diferentes de ser; a fala não é elevação de um comportamento perceptivo primeiro, certa sublimação ou maior sutileza face a um solo mudo, tal como pensa Merleau-Ponty. O fora é sempre já falante. Nesse sentido, temos o seguinte:

A manhã raia. Não: a manhã não raia./ A manhã é uma cousa abstrata, está, não é uma cousa./ Começamos a ver o sol, a esta hora, aqui./ Se o sol matutino dando nas árvores é belo,/ É tão belo se chamarmos à manhã

CAMARGO, Jeovane. Da coisa - de se a frequentam outras coisas. Griot : Revista de Filosofia, Amargosa - BA, v.19, n.2, p.135-153, junho, 2019. 
"começarmos a ver o sol"/ Como o é se lhe chamarmos a manhã;/ Por isso não há vantagem em pôr nomes errados às cousas,/ Nem mesmo em lhes pôr nomes alguns. (PESSOA, 2005, p. 136)

À primeira vista, ao dizer que a manhã é uma coisa abstrata, o poeta parece dizer que, por um lado, existem as coisas, e, por outro, os nomes que utilizamos para nos referirmos a elas e ordená-las. De maneira que dizer "manhã" seria algo abstrato em face do fato de começarmos a ver o sol com nossos sentidos. Todavia, "manhã" é algo abstrato por não ser tão exato quanto o fato de "começarmos a ver o sol", pois não é a manhã que raia, senão que o sol. A manhã "está" como coisa, isto é, está como coisa posta, não como a coisa vista (o sol a aparecer). E ainda que seja belo dizer "manhã", é tão belo quanto e ainda mais exato dizer "começamos a ver o sol". Assim, não é necessário acrescentar nomes às coisas, se nesse acrescentar coloca-se algo a mais nas coisas, algo que lá não está. Começamos a ver o sol, isso é um fato (uma coisa, na linguagem do poeta). A manhã raia, isso é já abstração, posto que nenhuma manhã raia, nem é uma coisa vista. Assim, não há vantagem em pôr nomes errados às coisas ou acontecimentos. E se não há vantagem "Nem mesmo em lhes pôr nomes alguns", esse verso precisa ser entendido no contexto em que ele aparece. "Pôr nomes nas coisas" significa ali acrescentar abstratamente algo às coisas; o que quer dizer também que a linguagem está sendo tomada como rótulo verbal para as coisas que existiriam silenciosamente. Isso não significa que o poeta assuma essa concepção dualista da linguagem, mas que ele a enuncia para mostrar que, partindose dela, cai-se em abstrações, como, por exemplo, que a palavra é nome para a coisa que existe antepredicativamente. Não há vantagem em pôr nomes nas coisas, se se parte da dicotomia coisa e palavra, pois assim não se vê a realidade, tal como não a vemos quando lhe pomos nomes errados (abstratos). Portanto, não há vantagem tanto em dar nomes errados como em entender que as palavras são meros nomes para as coisas. Dessa maneira, se "somos exterior essencialmente", é porque a linguagem não está dentro, mas é ela também fora, a realidade imediata que temos: "Sim, antes de sermos interior, somos exterior" (PESSOA, 2005, p. 120).

Em outro poema, ao recusar a mística de São Francisco de Assis, a qual consistia em acrescentar parentesco às coisas, como chamar "minha irmã à água", Caeiro termina dizendo:

Se eu lhe chamar minha irmã,/ Ao chamar-lhe minha irmã, vejo que o não é/ E que se ela é a água o melhor é chamar-lhe água;/ Ou, melhor ainda, não lhe chamar cousa nenhuma,/ Mas bebê-la, senti-la nos pulsos, olhar para ela/ E tudo isto sem nome nenhum. (PESSOA, 2005, p. 106).

Ora, a água, assim como a pedra, "não tem parentesco nenhum comigo" (PESSOA, 2005, p. 91); por isso, ao invés de acrescentar coisas à coisa, diga-se apenas pedra ou água. E o verso que enuncia "sem nome nenhum", relacionado ao contexto dos outros versos de Caeiro que tratam da linguagem, não deve ser lido como se houvesse uma apreensão das coisas sem predicação, ou de forma silenciosa. Ao contrário, eles dizem que a água, por exemplo, é a água, isto é, que a água que vejo é já a linguagem que falo, ou ainda, que a água só pode ser vista quando ao mesmo tempo (imediatamente) é dita. A água só pode ser vista (compreendida) como água na medida em que é já linguagem. E não há como isso se dar de forma diferente, posto o

CAMARGO, Jeovane. Da coisa - de se a frequentam outras coisas. Griot : Revista de Filosofia, Amargosa - BA, v.19, n.2, p.135-153, junho, 2019. 
natural do homem ser já o seu cultural, isto é, fala, linguagem. Enfim, o verso diz que a linguagem é realidade imediata. Um mundo sem linguagem é algo do qual não temos a experiência. Assim, "sem nome nenhum" significa: a água sem que nela intervenha a diferença entre certa matéria mineral muda e a palavra água (rótulo verbal) que a ela se reportaria (ou que coincidira com a matéria muda).

V - Em Merleau-Ponty, a coisa é mais do que ela é, isto é, ela representa "outra coisa que ela mesma", ou está orientada "àquilo que ela não é", porque o presente (a coisa vista) é perpassado por perfis temporais. $O$ presente quer se passar pela "totalidade do ser", mas essa pretensão é sempre "malograda" porque o tempo não deixa de escoar. Desse modo, o presente, ou uma coisa, é sempre representativo daquilo que ele não é. Há um "não-ser", virtualidades, possibilidades perceptivas que se anunciam na coisa vista, isto é, ela é frequentada por seu passado e seu futuro. $O$ presente vivido reenvia a outras dimensões temporais, de maneira que ele não é ele mesmo, mas já outra coisa. Assim, há apenas uma pretensa plenitude da coisa vista, posto que, devido a seus perfis temporais, ela é "aquilo que ela não é". Segundo a PhP: "A pretensa plenitude do objeto e do instante só surge diante da imperfeição do ser intencional" (MERLEAU-PONTY, PhP, p. 447). Por "imperfeição do ser intencional" deve-se entender os desdobramentos dos perfis temporais, cujo escoar oferece a coisa sempre "aberta", sempre como "outra coisa que ela mesma", de maneira que há sempre um excesso da coisa em relação a si mesma.

Ora, segunda a lógica da PhP, o tempo sempre passa adiante, ele é um "ir além", porque, tal como o impulso de significar na fala falante (inédita), ele é uma "carência que procura se preencher" (MERLEAU-PONTY, PhP, p. 250). Assim, no cerne dos desdobramentos temporais há uma falta (manque), uma forma vazia (forme vide), um "nada ativo" (néant actif), uma "dimensão de ausência" (dimension d'absence $)^{17}$ que faz da temporalidade certa insatisfação, uma carência sempre à procura de se preencher, mas que nunca alcança seu preenchimento (sua satisfação) ${ }^{18}$.

Essa estrutura ontológica é retomada na segunda fase do pensamento de Merleau-Ponty. A instituição - A passividade (IP, 1954-55) diz pois que o medium da instituição é a libido:

medium da instituição: a libido: é o devir da relação total com o mundo e o outro enquanto efetivo e não oficial, não imaginário. A história verdadeira de nossos investimentos, de nossas polaridades. Vivida e desconhecida como toda dimensão [...]. Instituição: estabelecimento de uma dimensão. (MERLEAU-PONTY, IP, p. 61)

Por sua vez, os cursos que formam $A$ Natureza (N, 1956-1960) entendem a vida como "a realidade de uma passagem" (MERLEAU-PONTY, N, p. 256; grifo meu), isto é, como escoar temporal. Na animalidade, essa passagem é "uma atividade pelo prazer" (MERLEAU-PONTY, N, p. 312, 313; grifo meu). E tal atividade pelo prazer no animal, por um processo de "elevação" de estruturas, torna-se corpo libidinal no

17 MERLEAU-PONTY. Phénoménologie de la perception, ps. 179, 193, 274.

${ }^{18}$ Aberto ao mundo por meio de uma perspectiva, o sujeito sente "a angústia de ser ultrapassado" pela totalidade da experiência (MERLEAU-PONTY, PhP, p. 489; grifo meu).

CAMARGO, Jeovane. Da coisa - de se a frequentam outras coisas. Griot : Revista de Filosofia, Amargosa - BA, v.19, n.2, p.135-153, junho, 2019. 
homem: "o desejo humano emerge do desejo animal" (MERLEAU-PONTY, N, p. 361). Dessa forma, a imbricação corpo e mundo se faz como um "vazio sempre futuro" (MERLEAU-PONTY, N, p. 340), porque a percepção é sempre parcial, embora esteja continuamente orientada à totalidade. A Natureza é uma atividade pelo prazer, um "desejo de relaxamento", de "gratificação ilimitada", desejo de um absoluto ou infinito que nunca é alcançado de fato, embora este direcione, por exemplo, o amadurecimento do embrião.

E O visível e o invisível (VI, 1964) retomará essa estrutura ao comentar que o visível "reside sempre "mais longe", que o mundo é um conjunto em que cada parte abre dimensões ilimitadas, de maneira que o sensível, a carne ou o quiasma, é a "Urpräsentation do Nichturpräsentiebar" (apresentação originária do originariamente não apresentável). A coisa, portanto, é sempre mais do que ela mesma, ela possui uma profundidade que consiste na "dimensão do oculto", a vera carne do mundo (Cf. MERLEAU-PONTY, VI, Notas de Nov. de 1959, ps. 201, 203). Desse modo, a sensibilidade própria do sensível e do corpo, o entrecruzamento de tecidos, o sensível, carne ou quiasma dizem respeito a que, "no trabalho paciente e silencioso do desejo, começa o paradoxo da expressão" (MERLEAU-PONTY, VI, p. 140, grifo meu).

Barbaras, por seu lado, embora tenha descoberto a originalidade de Caeiro, entende a "pura presença" da coisa ainda como "excesso de presença", "fascinação" ou "saturação da presença" (BARBARAS, 2011, p. 223; grifo meu). A "não filosofia" de Caeiro teria como "intuito abranger aquilo que não é "filosófico", a saber, o fundo obscuro [...], a camada originária da experiência que precede qualquer pensamento" (BARBARAS, 2011, p. 217; grifo meu). Tal "fundo obscuro", ou "camada originária" seria pré-reflexivo e antepredicativo, precedendo pois a linguagem. Daí o problema exposto por Barbaras: "A dificuldade é portanto a de achar uma linguagem que não traia o sentido da presença, uma linguagem das coisas mesmas adequada ao seu silêncio" (BARBARAS, 2011, p. 114). Embora originalmente seja esse um problema da fenomenologia de Merleau-Ponty, Barbaras entende que, em face do existir antepredicativo das coisas, Caeiro teria encontrado uma linguagem poética capaz de expressá-lo. Ao proceder dessa maneira, Barbaras continua a pensar dicotomicamente mesmo quando se propõe interpretar a poesia caeiriana. Como visto acima, nada mais distante de Caeiro do que um dualismo entre coisas mudas e linguagem. Dois problemas básicos da fenomenologia de MerleauPonty são assim reproduzidos por Barbaras: a dicotomia entre percepção e linguagem e o excesso da coisa nela mesma (excesso de ser, possibilidades que frequentam uma coisa vista). Pode-se dizer mesmo que a noção de désir é uma explicitação da estrutura temporal ou mesmo da estrutura ontológica do sensível tal como essas noções são expostas por Merleau-Ponty. De fato, em Barbaras, a estrutura do désir se faz como uma falta (manque) que procura se preencher: "o próprio do desejo é que o desejado não o preenche senão o atiçando" (BARBARAS, 1999, p. 137); assim, tal como em Merleau-Ponty, o mundo de Barbaras "corresponde a essa totalidade intotalizável, a esse invisível que toda percepção ao mesmo tempo atualiza e carece (manque)" (BARBARAS, 1999, p. 154).

Caeiro, contudo, não deixa de negar tal excesso de ser que frequentaria a coisa, como já visto acima. E ele ainda se posiciona contrariamente a tal compreensão da Realidade, ou da coisa, entendida como insatisfação, carência ou désir. Nesse sentido,

CAMARGO, Jeovane. Da coisa - de se a frequentam outras coisas. Griot : Revista de Filosofia, Amargosa - BA, 
temos os seguintes versos: "Que perfeito que é nele o que ele é - o seu corpo,/ A sua verdadeira realidade que não tem desejos nem esperanças,/ Mas músculos e a maneira certa e impessoal de os usar" (PESSOA, 2005, p. 141). A verdadeira realidade do corpo, como, por exemplo, de um homem visto ao longe a andar, não são as ideias, esperanças ou desejos que ele tem, senão que o seu aparecer, o modo no qual tal homem é a cada vez - neste caso, o andar. Isso que aparece, a coisa, a Realidade, isto é, o corpo (posto que corpo é sempre o aquiescer a um modo de ser), enfim, o andar, não tem ideias, desejos ou esperanças: o andar é tal qual o andar, nada além dele mesmo, sem qualquer outra significação, sem excessos de ser ou frequentação de outras coisas. $\mathrm{O}$ andar do homem não anuncia ou reenvia a qualquer outra coisa. Por isso, ele é o "sistema antigo que faz pernas andar", ou ainda "a maneira certa e impessoal" de usar os músculos, pois o andar, o modo de ser, obriga, apropria-se, faz/é Realidade - não tem nada por trás ou além dele mesmo, seja temporalidade, desejo ou subjetividade que o faça ser o movimento que ele é. Sistema antigo, impessoal e certo: a cada vez o aparecer da Realidade, de um modo de ser ou de uma coisa. Não há excesso de significação frequentando uma coisa, ou temporalidade/intencionalidade, e nem mesmo uma estrutura ontológica pensada como désir (a insatisfação de uma coisa por não ser já oura coisa que ela mesma, ou a insatisfação da tomada parcial por não ser a tomada total). Por isso, diz Caeiro: "Enquanto vou na estrada antes da curva/ Só olho para a estrada antes da curva,/ Porque não posso ver senão a estrada antes da curva." (PESSOA, 2005, p. 88; grifo meu). A estrada antes da curva é somente a estrada antes da curva; ela não é frequentada ou assombrada (haunt, hanter) por outras coisas (a estrada para além da curva, por exemplo). $O$ "para além da curva" (o que se "anunciaria", em linguagem fenomenológica) é pois "aquilo que não vejo", e se não vejo, isso de nada "serve", isto é, não é a Realidade imediata, a coisa mesma. Nem mesmo se pode dizer que a curva se anuncia, pois antes de a curva aparecer, há só a estrada. A "estrada antes da curva" não diria que a curva se anuncia como futuro próximo, mas antes que a curva já apareceu, é coisa vista, exterior. Assim, a estrada antes da curva não anuncia nada para além de si mesma, sendo somente o que é. 


\section{Referências:}

BARBARAS, Renaud. Investigações Fenomenológicas - Em direção a uma fenomenologia da vida. Curitiba: Editora UFPR, 2011.

BARBARAS, Renaud. De l'être du phénomène. Grenoble: Millon,1991.

BARBARAS, Renaud. Le tournant de l'expérience. Paris: VRIN, 1998.

BARBARAS, Renaud. Le désir et la distance. Paris: Vrin, 1999.

BARBARAS, Renaud. Introdution à une phénoménologie de la vie. Paris : Vrin, 2008.

BARBARAS, Renaud. La vie lacunaire. Pais: Vrin, 2011.

BARBARAS, Renaud. Dynamique de la manifestation. Paris: Vrin, 2013.

BARBARAS, Renaud. "A phenomenology of life". In: Carman, T., Hansen M. (eds.). The Cambridge Companion to Merleau-Ponty. Cambridge: Camb. Univ. Press, 2005. (versão digital).

BADIOU, A. Pequeno manual de inestética. São Paulo: Estação Liberdade, 2002.

BIMBENET, É. Nature et Humanité. Le problème antropologique dans l'oeuvre de Merleau-Ponty. Paris: Vrin, 2004.

BRANDÃO, R. O. "Consciência e Modernidade em Fernando Pessoa". In: Actas do IV Congresso Internacional de Estudos Pessoanos - Secção Brasileira, vol. II. s/d

CARBONE, M. La visibilité de l'invisible. Hildesheim: OLMS, 2001.

COELHO, A. Pina. Os fundamentos filosóficos da obra de Fernando Pessoa. 2 vols. Lisboa: Editorial Verbo, 1971.

COELHO, J. P. Diversidade e unidade em Fernando Pessoa. São Paulo: EDUSP, 1977.

DASTUR, F. La phénomènologie en questions. Paris: VRIN, 2004.

FERRAZ, M. S. A. Fenomenologia e ontologia em Merleau-Ponty. SP: Papirus, 2009.

FOGEL, G. Sentir, ver, dizer. Rio de Janeiro: Mauad X, 2012.

GIL, J. O Espaço Interior. Lisboa: Editora Presença, 1994.

KUJAWSKI. Fernando Pessoa, o outro. São Paulo: Imprensa Oficial do Estado: 1967.

LIND, Georg R. Estudos sobre Fernando Pessoa. Lisboa: Casa da Moeda, 1981.

MERLEAU-PONTY, M. La Nature. Paris: Seuil, 1994.

MERLEAU-PONTY, M. A Natureza. Trad.: Álvaro Cabral. São Paulo: Martins Fontes, 2006b. (N)

MERLEAU-PONTY, M. Le monde sensible et le monde de l'expression. Cours au Collège de France, Notes, 1953. Genève: MetisPresse, 2011.

MERLEAU-PONTY, M. Le primat de la perception. Paris: Verdier, 1996.

MERLEAU-PONTY, M. Le visible et l'invisible. Paris: Gallimard, 1979.

MERLEAU-PONTY, M. O visível e o invisível. Trad.: José Arthur Gianotti e

Armando Mora de Oliveira. São Paulo: Perspectiva, 2007. (VI)

MERLEAU-PONTY, M. L'institution - la passivité. Paris: Belin, 2003. (IP)

MERLEAU-PONTY, M. Parcours Deux. Lagrasse: Verdier, 2000a. (PD)

MERLEAU-PONTY, M. Phénoménologie de la perception. Paris: Gallimard, 1995.

MERLEAU-PONTY, M. Fenomenologia da percepção. São Paulo: Martins Fontes, 2006. (PhP).

MOISÉS, C. F. O Poema e as Máscaras - Introdução à poesia de Fernando Pessoa. Florianópolis: Letras Contemporâneas, 1999.

CAMARGO, Jeovane. Da coisa - de se a frequentam outras coisas. Griot : Revista de Filosofia, Amargosa - BA, 
MOURA, C. A. R. Racionalidade e crise. SP: Discurso Editorial e Editora UFPR, 2001.

MOUTINHO, Luiz Damon S. Razão e experiência. Rio de Janeiro: UNESP, 2006.

MOUTINHO, Luiz Damon S. Merleau-Ponty e a "filosofia da consciência". In: Merleau-Ponty. Revista Dois pontos. Curitiba, São Carlos, vol. 9, n. 1, abril de 2012.

PAZ, O. Signos em Rotação. São Paulo: Editora Perspectiva, 1976.

PERRONE-MOISÉS, L. Fernando Pessoa: Aquém do eu, além do outro. São Paulo: Martins Fontes, 1982.

PESSOA, F. Alguma Prosa. 5 ${ }^{\text {a }}$ ed. Rio de Janeiro: Nova Fronteira, 1990a.

PESSOA, F. Escritos autobiográficos, automáticos e de reflexão pessoal. São Paulo: A Girafa, 2006a.

PESSOA, F. Fausto, tragédia Subjetiva. Rio de Janeiro: Nova Fronteira, 1991.

PESSOA, F. Livro do Desassossego. São Paulo: Cia. das Letras, 1999.

PESSOA, F. Notas para Recordação do meu Mestre Caeiro. Lisboa: Presença, 1997

PESSOA, F. Poesia completa de Alberto Caeiro. São Paulo: Cia. das Letras, 2005.

PESSOA, F. Poesia Completa de Álvaro de Campos. São Paulo: Cia. das Letras, 2002.

PESSOA, F. Prosa de Álvaro de Campos. Lisboa: Ática, 2012.

PESSOA, F. Textos Filosóficos - Vol. I. Lisboa: Nova Ática, 2006b.

RAMOS, S. S. A prosa de Dora : uma leitura da articulação entre natureza e cultura na filosofia de Merleau-Ponty. São Paulo : Edusp, 2013. (versão digital)

RICHIR, Marc et TASSIN, Etienne. Merleau-Ponty: phénoménologie et expériences. Grenoble: Jérôme Millon, 1992.

SAINT AUBERT, E. Vers une ontologie indirecte. Paris: Vrin, 2006.

SAINT AUBERT, E. Etre et chair I - Du corps au désir. Paris: Vrin, 2013.

SEABRA, J. A. Fernando Pessoa ou o poetodrama. São Paulo: Perspectiva, 1991.

SILVA, L. O. O materialismo idealista de Fernando Pessoa. Lisboa: Clássica, 1985.

Autor(a) para correspondência: Jeovane Camargo,Universidade Federal de São Carlos, Departamento de Filosofia e Metodologia das Ciências, Rod. Washington Luiz, 13565-905, São Carlos-SP, Brasil. acasadeasterion@gmail.com 